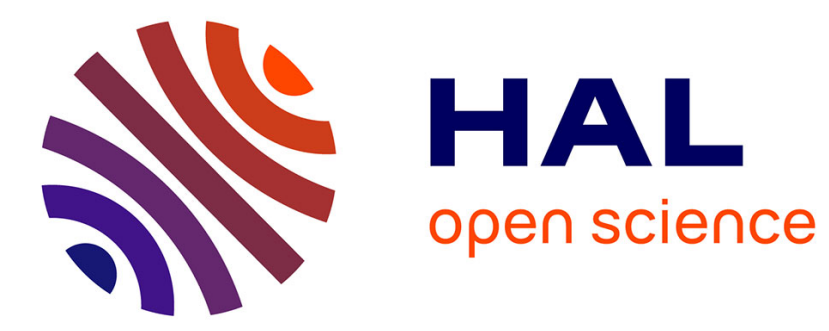

\title{
Polymorphism of 2-Adamantanone
}

Philippe Négrier, M. Barrio, M. Romanini, Josep Lluis Tamarit, Denise

Mondieig, A. I. Krivchikov, L. Kepinski, A. Jezowski, D. Szewczyk

\section{To cite this version:}

Philippe Négrier, M. Barrio, M. Romanini, Josep Lluis Tamarit, Denise Mondieig, et al.. Polymorphism of 2-Adamantanone. Crystal Growth \& Design, 2014, 14 (5), pp.2626-2632. $10.1021 / \operatorname{cg} 500313 \mathrm{~m}$. hal-00999243

\section{HAL Id: hal-00999243 https://hal.science/hal-00999243}

Submitted on 8 Jan 2018

HAL is a multi-disciplinary open access archive for the deposit and dissemination of scientific research documents, whether they are published or not. The documents may come from teaching and research institutions in France or abroad, or from public or private research centers.
L'archive ouverte pluridisciplinaire HAL, est destinée au dépôt et à la diffusion de documents scientifiques de niveau recherche, publiés ou non, émanant des établissements d'enseignement et de recherche français ou étrangers, des laboratoires publics ou privés.

\section{다(1)(2)}

Distributed under a Creative Commons Attribution - ShareAlikel 4.0 International 


\title{
Polymorphism of 2-adamantanone
}

\author{
P. Negrier ${ }^{1}$, M. Barrio ${ }^{2}$, M. Romanini ${ }^{2}$, J. Ll. Tamarit ${ }^{2, *}$, D. Mondieig ${ }^{1}$, A.I.
} Krivchikov $^{3}$, L. Kepinski ${ }^{4}$, A. Jezowski ${ }^{4}$, D. Szewczyk ${ }^{4}$

${ }^{1}$ Univ. Bordeaux, LOMA, UMR 5798, F-33400 Talence, France

CNRS, LOMA, UMR 5798, F-33400 Talence, France.

${ }^{2}$ Grup de Caracterització de Materials, Department de Física i Enginyeria

Nuclear, ETSEIB, Diagonal 647, Universitat Politècnica de Catalunya, 08028

Barcelona, Catalonia (Spain)

${ }^{3}$ B. Verkin Institute for Low Temperature Physics and Engineering of NAS

Ukraine, 47 Lenin Ave., Kharkov 61103, Ukraine

${ }^{4}$ Institute of Low Temperature and Structure Research, Polish Academy of

Sciences, ul. Okólna 2, 50-422 Wroclaw, Poland

* josep.1luis.tamarit@upc.edu

\begin{abstract}
The polymorphism of 2-adamantanone $\left(\mathrm{C}_{10} \mathrm{H}_{14} \mathrm{O}\right)$ has been investigated by means of X-ray diffraction and high-pressure thermal analysis. The intricate behavior of the low-temperature crystalline phases has been disentangled. The stable phase has been found to be orthorhombic $\left(C m c 2_{1}, \mathrm{Z}=4\right)$, fully ordered, with lattice parameters $a=6.8884(18) \AA, b=10.830(3) \AA, c=10.658(3) \AA$, $\mathrm{V} / \mathrm{Z}=198.8(1) \AA^{3}$. The metastable phase was determined to be monoclinic $\left(P 2_{1} / c, Z=4\right)$ with lattice parameters $a=6.5920(17) \AA, \quad b=11.118(3) \AA$, $c=12.589(3) \AA, \beta=118.869(11)^{\circ}, V / Z=202.0(1) \AA^{3}$. The pressure-temperature phase diagram irrefutably shows the stability relation between both phases and, accordingly, the long-time unknown polymorphic behavior is now revealed and gives coherent physical explanation of the literature published so far.
\end{abstract}




\section{Introduction}

In the general context of chemical engineering diamondoid molecules is an attractive class of hydrocarbons fully $\mathrm{sp}^{3}$-hybridized formed by three or more rigidly interlocked cyclohexane rings. They have recently received great interest due to their unique structures and their chemical and physical properties making them promising candidates for building blocks for selfassembled processes in a huge number of applications. ${ }^{1-6}$ The main interest is to build up organic crystals with large and dimensionally fixed and tuned cavities giving rise to porous materials with the desired chemical and physical needs.

The pristine and thus the smallest diamondoid molecule is the adamantane, a rigid molecule with point group symmetry $\mathrm{T}_{\mathrm{d}}$ formed by 10 carbon atoms arranged as a single diamond cage surrounded by 16 hydrogen atoms. ${ }^{7}$ Despite the rigid molecular skeleton adamantane exhibits a series of thermally induced solid-solid phase transitions before melting that are known to be the consequence of the ability to gain rotational degrees of freedom in the crystalline state (orientationally disordered, OD, phases) mainly due to the little hindrance for reorientational processes associated to its globular shape. ${ }^{8,9}$ The OD phase is characterized by long-range positional order, commonly of high symmetry as cubic or hexagonal, whereas the reorientations of molecules take place among a set of distinguishable number of equilibrium orientations. Such a disorder gives rise to high-vapor pressure and low entropy of fusion, in general less than $2.5 R, R$ the universal gas constant, which is known as Timmermans' criterium. ${ }^{10,11}$

A set of adamantane derivatives can be obtained substituting one or two hydrogen atoms by an atom $(\mathrm{Cl}, \mathrm{Br}, \mathrm{O}, \ldots)$ or a group of atoms $\left(\mathrm{CN}, \mathrm{OH}, \mathrm{CH}_{3}\right.$, $\mathrm{CH}_{2} \mathrm{OH}, \mathrm{NH}_{2}, \ldots$ ) into a tertiary or secondary carbon, given rise to the $1-\mathrm{X}$ - or 2-X-adamantane compounds, respectively. The former give rise to molecules with $\mathrm{C}_{3 \mathrm{v}}$ point group symmetry and both polymorphic behavior as well as dynamic properties have been extensively studied. ${ }^{12-18}$ As for the latter, with $\mathrm{C}_{2 \mathrm{v}}$ symmetry, the literature studies are scarce and, concerning the polymorphic behavior as a function of temperature and pressure, there are some hints but sometimes contradictory. ${ }^{19-31}$ 
Among the 2-X-adamantane derivatives, 2-O-adamantane (2-adamantanone, $\mathrm{C}_{10} \mathrm{H}_{14} \mathrm{O}$, hereinafter called 2O-A) has probably been the most studied in the OD phase. The polymorphic behavior of this compound has been described as follows. The OD room temperature phase melts at $529 \mathrm{~K}$ and exhibits a facecentered cubic structure (space group Fm $\overline{3} \mathrm{~m}$ ). ${ }^{16,19,27}$ On cooling the OD phase it transforms at around $178 \mathrm{~K}$ to an "ordered" low-temperature phase, which comes back to the OD phase on heating at ca. $205 \mathrm{~K} \cdot{ }^{19,20,30,31} \mathrm{~A}$ large number of works has been published concerning the orientational disorder of the OD phase, whereas the low-temperature phase was found to be perfectly ordered through NMR studies. ${ }^{19-31}$ Nevertheless, recent dielectric spectroscopy analyses and X-ray diffraction have shown that a statistical intrinsic disorder concerning the site occupancy of the oxygen atom along different sites giving rise to large-angle molecular rotations associated to time-average fluctuations of the molecular dipole exist. ${ }^{24}$ As a consequence of such a disorder the dielectric spectra showed the universal features of glass-like materials in which $\alpha$ - and $\beta$-relaxation processes appear. Butler et al. ${ }^{19}$ submitted the $2 \mathrm{O}$-A to a thermal cycling at normal pressure between 150 and $250 \mathrm{~K}$, i.e., around the low-temperature to OD phase transition. As a result, the transition temperature from the low-temperature to the OD phases shifted from 205 till $221 \mathrm{~K}$ (see Table 1), which in fact means that a new low-temperature (stable) phase appeared at the expense of the low-temperature (metastable) phase. The authors discarded the usual explanation related to the increase of crystal defects when thermal cycling and proposed the possibility of appearance of new both low- and high-temperature phases. The difficulty of the conversion from the OD FCC phase to the low-temperature stable phase was highlighted by Bazyleva et al. ${ }^{20}$ through adiabatic calorimetry. After long time annealing, transition temperature on heating was determined to be $216.4 \mathrm{~K}$, close to that obtained by Butler et al. after temperature cycling around the transition.

Table 1. Thermodynamic properties of the transitions between stable (s) and metastable (m) phases for 2-adamantanone. 


\begin{tabular}{|c|c|c|c|}
\hline \multirow[b]{2}{*}{ Property } & \multicolumn{2}{|c|}{ Transition } & \multirow[b]{2}{*}{$\mathrm{FCC}^{\mathrm{S}} \rightarrow \mathrm{L}^{\mathrm{S}}$} \\
\hline & $\mathrm{O}^{\mathrm{S}} \rightarrow \mathrm{FCC}^{\mathrm{S}}$ & $\mathrm{M}^{\mathrm{m}} \rightarrow \mathrm{FCC}^{\mathrm{S}}$ & \\
\hline \multirow[t]{3}{*}{$\mathbf{T}_{\mathbf{c}} / \mathrm{K}$} & & $203.6 \pm 1.0$ & $557.4 \pm 1.0$ \\
\hline & $221^{\mathrm{a}}$ & $205^{\mathrm{a}}$ & \\
\hline & $216.4 \pm 0.1^{\mathrm{c}}$ & - & $557.5 \pm 0.2^{\mathrm{c}}$ \\
\hline \multirow[t]{3}{*}{$\Delta \mathbf{H} / \mathrm{kJ} \mathrm{mol}^{-1}$} & $7.82 \pm 0.57^{b}$ & $4.59 \pm 0.50$ & $10.4 \pm 1.0$ \\
\hline & $7.93^{\mathrm{a}}$ & $3.7^{\mathrm{a}}$ & \\
\hline & $7.627 \pm 0.014^{\mathrm{c}}$ & - & $11.77 \pm 0.24^{\mathrm{c}}$ \\
\hline \multirow[t]{3}{*}{$\Delta \mathbf{S} / \mathrm{J} \mathrm{mol}^{-1} \mathrm{~K}^{-1}$} & & $22.4 \pm 2.4$ & \\
\hline & $35.9^{\mathrm{a}}$ & $18.0^{\mathrm{a}}$ & \\
\hline & $29.18 \pm 0.07^{\mathrm{c}}$ & & $21.1 \pm 0.4^{\mathrm{c}}$ \\
\hline$\Delta \mathbf{v}^{\mathbf{R X}}(\mathrm{p}=0.1 \mathrm{MPa}) / \mathrm{cm}^{3} \mathrm{~mol}^{-1}$ & $6.54 \pm 0.33$ & $3.86 \pm 0.58$ & \\
\hline$\Delta \mathbf{v}^{\mathbf{H P}}(\mathrm{p}=0.1 \mathrm{Mpa}) / \mathrm{cm}^{3} \mathrm{~mol}^{-1}$ & $6.09 \pm 0.43^{\mathrm{d}}$ & & \\
\hline$(\mathbf{d T} / \mathbf{d p})^{\exp / \mathrm{K} \mathrm{MPa}^{-1}}$ & $0.181 \pm 0.004$ & $0.171 \pm 0.033^{b}$ & \\
\hline
\end{tabular}

${ }^{\mathrm{a}}$ From ref. 19; ${ }^{\mathrm{b}}$ Calculated from Clauius-Clapeyron; ${ }^{\mathrm{c}}$ From ref. 20;

${ }^{\mathrm{d}}$ Extrapolated from high-pressure values in ref. 22

The transition between the low-temperature and OD phase has been also revealed by application of pressure at room temperature. Hara et al. ${ }^{22}$ found that the OD FCC phase reversibly transforms to a tetragonal ordered structure $\left(\mathrm{a}=7.15 \AA, \mathrm{c}=7.82 \AA, \mathrm{V}=399.8 \AA^{3}\right)$ at $8.0 \pm 0.5 \mathrm{kbar}$ at $301 \mathrm{~K}$. It should be noticed that the adscription of the new high-pressure phase to the tetragonal system was performed by assuming the similarities with the high-pressure phase of adamantane ${ }^{32}$ due to the reduced number (only 3) of Bragg peaks and, according to the lattice volume the tetragonal cell should contain 2 molecules. Shortly after Hara et al. $^{22}$ measured the relative volume as a function of pressure for 2O-A. It is well-known that increasing pressure (or decreasing temperature) gives rise to large hysteresis (4 kbar for the adamantanone according to the authors) and thus transition pressure must be assigned when pressure is slowly decreased in order to attain the equilibrium conditions, the authors assigned the transition pressure to the average of the increasing/decreasing experiments. Nevertheless, by reading directly in the $\Delta V / V$ vs. $P$ recorded experimental lines of the published work, a pressure of 4.3 kbar at $273 \mathrm{~K}$ can be determined. In addition, the authors gave the volume variation along the coexistence curve for a number of states, displaying that such a variation decreases with increasing pressure. A high-pressure Raman study $^{23}$ suggested that normal pressure low-temperature phase at $150 \mathrm{~K}$ and high-pressure (higher than $6.9 \mathrm{kbar}$ ) room temperature are one and the same. The published work emphasized that, as a result of the Raman spectroscopic 
analysis, the high-pressure lattice should contain at least 4 molecules (and not 2 as inferred from the crystallographic study of Hara et al. ${ }^{22}$ ).

In the present paper, the crystal structures of stable and metastable phases of 2O-A are presented, together with the equilibrium pressure-temperature line for the coexistence between the stable low-temperature and the OD FCC phases to verify the stability of the involved phases.

\section{Experimental Section}

2.1. Materials. 2-O-adamantane was purchased from Aldrich with purity of $99+\%$ and was used without further purification.

\subsection{Differential Thermal Calorimetry at normal pressure. Calorimetric} measurements at normal pressure were conducted by means of a Q100 thermal analyzer from TA Instruments. Heating and cooling rates of $2 \mathrm{~K} \mathrm{~min}^{-1}$ and sample masses around $15 \mathrm{mg}$ gathered in Perkin-Elmer high-pressure stainless steel pans were used to avoid spurious signals as a consequence of the deformation of the pans due to the high vapor pressure of material.

2.3. High-Pressure Differential Thermal Analysis. High-pressure calorimetric measurements were performed at a heating rate of $2 \mathrm{~K} \mathrm{~min}^{-1}$ using an in-house built high-pressure differential thermal analyzer similar to $\mathrm{Wu} \square \mathrm{rflinger}$ 's apparatus $^{33}$ working in the temperature range from $150 \mathrm{~K}$ to $473 \mathrm{~K}$ and 0 and $300 \mathrm{MPa}$. To ascertain that in-pan volumes were free from residual air, specimens were mixed with an inert perfluorinated liquid (Galden, from Bioblock Scientifics, Illkirch, France) as a pressure-transmitting medium, and the mixtures were sealed into cylindrical tin pans. Perfluorinated liquid was chemically inactive for 2O-A as demonstrated by DSC measurements carried out on a Galden+2O-A mixture with the TA Instruments Q100 under ordinary conditions.

2.4 Scanning Electron Microscopy. Morphology of grains was followed by means of SEM. A cylindrical sample $5 \mathrm{~mm}$-diameter and $12 \mathrm{~mm}$-length was prepared from raw material (grain size was in range $50-200 \mu \mathrm{m}$ ) by press. Morphology was examined before and after first cooling down to $77 \mathrm{~K}$ and then heating by FE-SEM by using a FEI Nova NanoSEM 230 microscope at room temperature. SEM images were acquired in the low vacuum mode (60 Pa 
$\mathrm{H}_{2} \mathrm{O}$ ) using LVD (low vacuum detector) working in SE (secondary electrons) mode with a $3 \mathrm{kV}$ primary electron beam acceleration voltage.

\subsection{High-resolution $X$-ray powder diffraction measurements}

High-resolution X-ray diffraction patterns were recorded using a horizontally mounted INEL cylindrical position-sensitive detector (CPS120) ${ }^{34}$ using DebyeScherrer geometry (angular step ca. $0.029^{\circ}-2 \theta$ over a $2 \theta$-range from 2 to $120^{\circ}$ ). The system is equipped with a liquid nitrogen 600 series Cryostream Cooler from Oxford Cryosystems with a temperature accuracy of $0.1 \mathrm{~K}$ and similar for fluctuations. X-ray profiles were acquired isothermically (no less than $60 \mathrm{~min}$ ) upon cooling first then heating back so that the temperature range was scanned at intervals of ca. $20 \mathrm{~K}$ and less when the transition was approached.

Monochromatic $\mathrm{Cu} \mathrm{K} \alpha_{1}(\lambda=1.5406 \AA)$ radiation powered with $1.0 \mathrm{~kW}(40 \mathrm{kV}$ and $25 \mathrm{~mA}$ ) was selected. External calibration using the $\mathrm{Na}_{2} \mathrm{Ca}_{2} \mathrm{Al}_{2} \mathrm{~F}_{14}$ cubic phase mixed with Silver Behenate was performed by means of cubic spline fittings.

To prevent patterns from possible effects of preferred orientations, samples were introduced into $0.3-\mathrm{mm}$ diameter Lindemann capillaries which were rotated perpendicular to the X-ray beam direction.

Crystal structures have been resolved by using the modules Powder Indexing for cell searching, the Powder Refinement for full profile determination after pseudo-Voigt fittings ${ }^{35}$ and the module Powder Solve ${ }^{36}$ of the Materials Studio application. ${ }^{37}$ Finally, to optimize the crystal structure with the lowest $R_{w p}$, Rietveld refinement was used.

\section{Experimental Results and Discussion}

A capillary with the as-received sample was cooled down to $90 \mathrm{~K}$ and X-ray powder diffraction measurements were conducted from 90 to $400 \mathrm{~K}$. Patterns were collected every $20 \mathrm{~K}$ until $190 \mathrm{~K}$ and every $5 \mathrm{~K}$ around the lowtemperature to the OD FCC phase transition, which appeared at $205 \mathrm{~K}$ as it is demonstrated by the coexistence of both phases at such temperature (Figure 1). The lattice of the low-temperature phase (at $\mathrm{T}$ lower than $205 \mathrm{~K}$ ) was determined by means of X-Cell software, available in the module Powder Indexing of Materials Studio. 
Systematic absences enable to determine the space group, which was compatible with $P 2_{1} / c$ space group. According to a reasonable density, $\mathrm{Z}=4$ was assigned. A rigid body molecule was built up by using the cage body obtained for similar adamantane derivatives. ${ }^{12}$

Pawley refinement was carried out using the initial unit-cell parameters in space group $P 2_{1} / c$. The unit-cell parameters, zero-point shift, background, peak profile (pseudo-Voigt) and peak asymmetry parameters were refined (see Table 2). The constructed molecule was then placed in a general position within the unit cell and the module Powder Solve was used to solve the structure. Multiple refinements were performed with oxygen atoms occupying possible positions according to the molecular structure. Those with low values of the refined occupancy factor were successively discarded and, finally the occupancy factors of the three remaining sites gave rise to values close to $25 \%$, $25 \%$ and $50 \%$, these being fixed for the next refinements.

In the final Rietveld refinement, the position and orientation of the molecule was refined with the rigid-body constraint, and with a single overall isotropic displacement parameter. All of the profile parameters referred to above were also refined, and preferred orientation was fitted using the Rietveld-Toraya function. ${ }^{38,39}$ An example of the experimental and refined patterns is shown in

\section{Figure 1.}
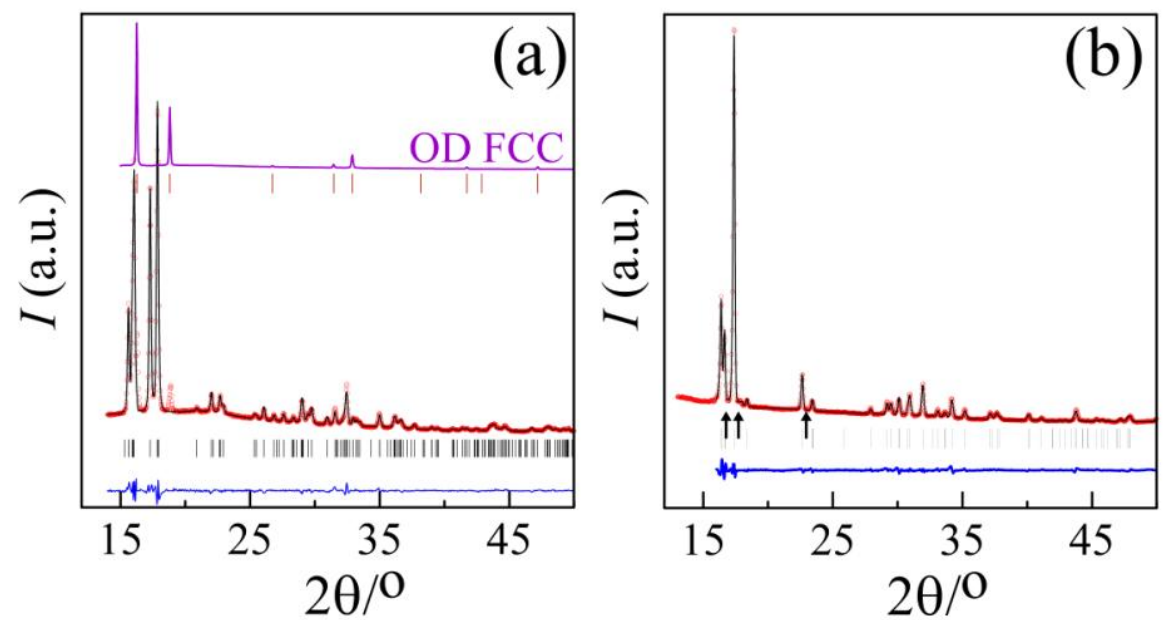

Figure 1. (a) Experimental X-ray diffraction pattern of the OD FCC phase of 2-adamantanone at $205 \mathrm{~K}$ with Bragg reflections as vertical sticks. Bottom pattern: Experimental (red circles) and calculated (black line) X-ray diffraction 
patterns along with the difference profile (blue line) and Bragg reflections (vertical sticks) for the final Rietveld refinement of $P 2{ }_{1} / c$ monoclinic $\left(\mathrm{M}^{\mathrm{m}}\right)$ phase of 2-adamantanone at $190 \mathrm{~K}$. Bragg reflections of the OD FCC phase can be seen coexisting with those of the monoclinic phase. (b) Experimental (red circles) and calculated (black line) X-ray diffraction patterns along with the difference profile (blue line) and Bragg reflections (vertical sticks) of $C m c 2_{1}$ orthorhombic phase of 2-adamantanone (at $190 \mathrm{~K}$ ).Vertical arrows correspond to the position of the Bragg peaks found by Hara et al. ${ }^{21}$ at room temperature and $10 \mathrm{kbar}$.

The as-received sample was prepared by pressing the powder for scanning electron microscopy. Grain size of the initial as-received sample was in the range $50-200 \mu \mathrm{m}$ and the surface was found uneven and with very irregular grain boundaries (Figure 2, left panel). After one cycle between $77 \mathrm{~K}$ and room temperature well defined regions with flat surfaces and sharp edges, characteristics for crystalline materials, appear (see Figure 2, central panel) After five thermal cycles (Figure 2, right panel), the grain sizes are more uniform and clearly defined, so showing the increase of crystallinity. Such a change of the morphology highlights the changes observed by Butler et al. ${ }^{19}$ by temperature cycling.

The same experimental protocol was repeated with a sample into a capillary for X-ray diffraction. After ca. 10 cycles, the low-temperature monoclinic phase did not appear and a new pattern emerged (Figure 2, right panel). The procedure to determine the structure was similar to that used for the monoclinic form. Nevertheless, in this case, taking into account $Z^{\prime}=0.5$, the molecule was placed on the mirror perpendicular to the $\mathrm{X}$-axis reducing the parameters to be found and so final Rietveld refinement was combined with minimization of the lattice energy. Final results are gathered in Table 2. 

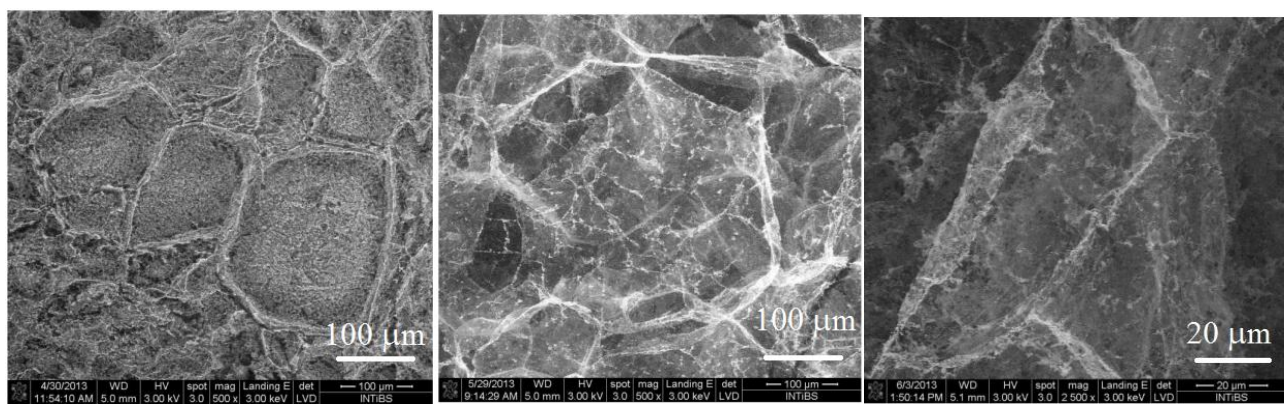

Figure 2. SEM photographs of 2-adamantanone powdered sample before temperature cycling (left panel, magnification of 500), after one cycle between $77 \mathrm{~K}$ (central panel, magnification of 500) and room temperature and after five cycles (right panel, magnification of 2500) showing that grain sizes diminish with temperature cycling.

Table 2. Results from the Rietveld refinement of the metastable monoclinic $\left(\mathrm{M}^{\mathrm{m}}\right)$ and stable orthorhombic $\left(\mathrm{O}^{\mathrm{s}}\right)$ low-temperature phases of 2adamantanone.

\begin{tabular}{|c|c|c|}
\hline Chemical Formula & \multicolumn{2}{|c|}{$\mathrm{C}_{10} \mathrm{H}_{14} \mathrm{O}$} \\
\hline $\mathrm{M} / \mathrm{g} \cdot \mathrm{mol}^{-1}$ & \multicolumn{2}{|c|}{150.2176} \\
\hline Phase & $\mathrm{M}^{\mathrm{m}}$ & $\mathrm{O}^{\mathrm{s}}$ \\
\hline 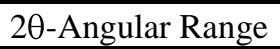 & $10-55^{\circ}$ & $15-80^{\circ}$ \\
\hline Space group & $P 2_{l} / c$ & $\mathrm{Cmc2}_{1}$ \\
\hline $\mathrm{a} / \AA$ & $6.5920 \pm 0.0017$ & $6.8884 \pm 0.0018$ \\
\hline $\mathrm{b} / \AA$ & $11.118 \pm 0.003$ & $10.830 \pm 0.003$ \\
\hline$c / \AA$ & $12.589 \pm 0.003$ & $10.658 \pm 0.003$ \\
\hline$\alpha /{ }^{\circ}$ & 90 & 90 \\
\hline$\beta /{ }^{\circ}$ & $118.869 \pm 0.011$ & 90 \\
\hline$\gamma /{ }^{\circ}$ & 90 & 90 \\
\hline $\mathrm{V} / \mathrm{Z} / \AA^{3}$ & $202.0 \pm 0.1$ & $198.8 \pm 0.1$ \\
\hline $\mathrm{Z}\left(\mathrm{Z}^{\prime}\right)$ & $4(1)$ & $4(0.5)$ \\
\hline Temperature & $190 \mathrm{~K}$ & $190 \mathrm{~K}$ \\
\hline $\mathrm{D}_{\mathrm{x}} / \mathrm{g} \cdot \mathrm{cm}^{-3}$ & $1.235 \pm 0.001$ & $1.255 \pm 0.001$ \\
\hline $\begin{array}{c}\text { Radiation type: } \\
\text { X-Ray, } \lambda\end{array}$ & $\lambda=1.5406 \AA$ & $\lambda=1.5406 \AA$ \\
\hline $\begin{array}{c}2 \theta \text {-shift (zero } \\
\text { correction) }\end{array}$ & $-0.0030 \pm 0.0013$ & $0.0529 \pm 0.0029$ \\
\hline \multicolumn{3}{|l|}{ Profile Parameters } \\
\hline $\mathrm{Na}$ & $0.513 \pm 0.008$ & $0.233 \pm 0.010$ \\
\hline \multicolumn{3}{|l|}{$\begin{array}{l}\text { Reliability } \\
\text { Parameters }\end{array}$} \\
\hline $\mathrm{R}_{\mathrm{wp}}$ & $3.70 \%$ & $4.22 \%$ \\
\hline $\mathrm{R}_{\mathrm{p}}$ & $2.75 \%$ & $3.07 \%$ \\
\hline $\begin{array}{l}\text { Peak width } \\
\text { parameters }\end{array}$ & & \\
\hline
\end{tabular}




\begin{tabular}{ccc}
\hline $\mathrm{U}$ & $0.350 \pm 0.089$ & $0.349 \pm 0.050$ \\
$\mathrm{~V}$ & $0.145 \pm 0.040$ & $0.060 \pm 0.024$ \\
$\mathrm{~W}$ & $0.005 \pm 0.004$ & $0.000 \pm 0.003$ \\
\hline $\begin{array}{c}\text { Overall isotropic } \\
\text { temperature factor, } \mathrm{U} \\
/ \AA^{2}\end{array}$ & $0.0622 \pm 0.0013$ & $0.0196 \pm 0.0009$ \\
\hline $\begin{array}{c}\text { Preferred Orientation } \\
\text { (Rietveld-Toraya } \\
\text { function) }\end{array}$ & \\
\hline $\mathrm{a}^{*}$ & $0.268 \pm 0.023$ & $-0.555 \pm 0.025$ \\
\hline $\mathrm{b}^{*}$ & $-0.003 \pm 0.076$ & $-0.240 \pm 0.038$ \\
\hline $\mathrm{c}^{*}$ & $0.964 \pm 0.006$ & $-0.796 \pm 0.020$ \\
\hline $\mathrm{G} 2$ & $-2.44 \pm 0.26$ & $-7.16 \pm 1.31$ \\
\hline $\mathrm{G} 1$ & $0.773 \pm 0.011$ & $0.712 \pm 0.032$ \\
\hline & & \\
\hline
\end{tabular}

After the determination of low-temperature structures, $\mathrm{M}^{\mathrm{m}}$ and $\mathrm{O}^{\mathrm{s}}$, lattice parameters were measured as a function of temperature for thermal-expansion and volume change at the transition purposes. The site occupancy of the oxygen atoms remains constant for the whole temperature range. The results are plotted in Figure 3. Pattern matching refinement was applied to the patterns collected for the OD FCC phase.

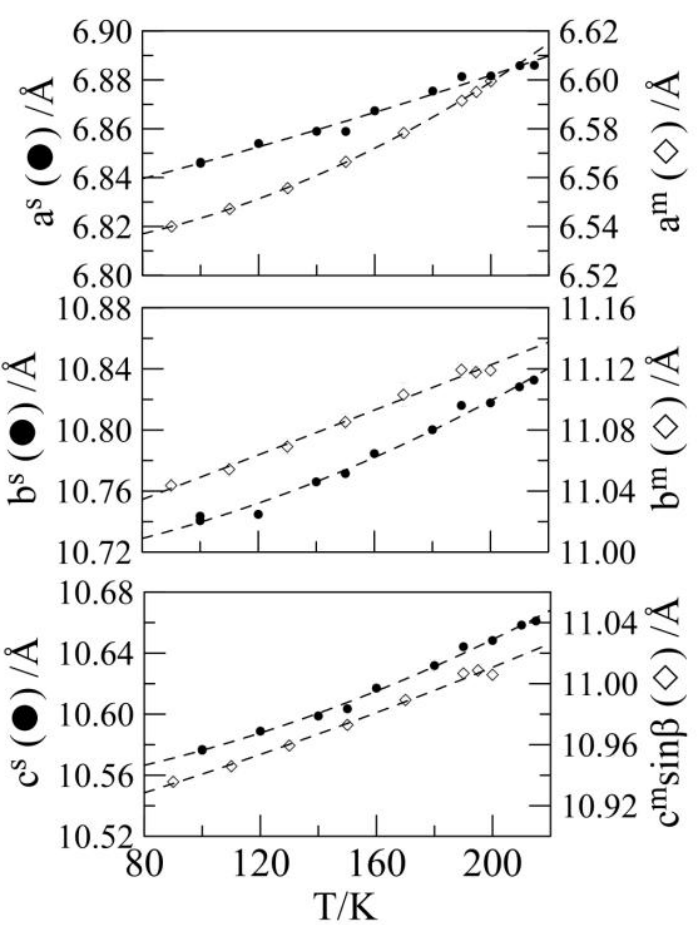

Figure 3. Lattice parameters of the low-temperature phases, stable $\mathrm{O}^{\mathrm{s}}$ (left axes, filled symbols) and metastable $\mathrm{M}^{\mathrm{m}}$ (right axes, empty symbols) as a function of temperature 
The so-obtained lattice parameters and unit cell volume were fitted by a standard least-squares method as a function of temperature and the polynomials describing such a temperature variation are compiled in Table 3. The volume values at each temperature, depicted in Figure 4, were used to calculate the volume change at the $\mathrm{M}^{\mathrm{m}}$ and $\mathrm{O}^{\mathrm{s}}$ to OD FCC transitions, 6.54 and $3.86 \mathrm{~cm}^{3}$ $\mathrm{mol}^{-1}$, respectively (Table 1). The last figure shows up that volume changes as a function of pressure previously determined from Hara et al. ${ }^{22}$ perfectly match the value for the $\mathrm{O}^{\mathrm{s}}$ to $\mathrm{OD} \mathrm{FCC}$ transition at normal pressure determined in this work, which means that the low-temperature phase obtained by increasing the pressure must correspond to the stable orthorhombic phase. In addition, volume changes as a function of pressure for the ordered to OD transition follows the typical variation for such kind of transitions. ${ }^{40-43}$

To check once again the stability of the orthorhombic phase, high-pressure thermal analyses were performed as a function of pressure. Figure 5a shows the obtained pressure-temperature phase diagram for the low-temperature to OD FCC phase transition. The diagram evidences that application of pressure stabilizes the orthorhombic phase because the extrapolation at normal pressure gives the value of $217 \mathrm{~K}$ which nicely agrees with the value obtained by adiabatic calorimetry ${ }^{20}$ and that obtained by Butler et al. ${ }^{19}$ after temperature cycling. Moreover, the high-pressure value of Hara et al. ${ }^{22}$ perfectly matches the equilibrium line determined in this work. Pressure transition at room temperature obtained by Harvey et al. ${ }^{23}$ by means of Raman spectroscopy $(6.9 \pm 0.2)$ kbar for a decompression measurement is certainly far away from our results. This transition point cannot be associated to the $\mathrm{M}^{\mathrm{m}}$ to OD FCC phase transition because of two reasons: (i) the same authors established that the high-pressure obtained phase is the same than that obtained at normal pressure and low-temperature and, (ii) because the equilibrium coexistence line for the $\mathrm{M}^{\mathrm{m}}$ to OD FCC transition is less steeper $\left(0.171 \mathrm{~K} \mathrm{MPa}^{-1}\right)$ than that of $\mathrm{O}^{\mathrm{s}}$ to OD FCC $\left(0.184 \mathrm{~K} \mathrm{MPa}^{-1}\right)$, as it can be calculated by Clausius-Clapeyron with the experimental enthalpy and volume changes for the $\mathrm{M}^{\mathrm{m}}$ to OD FCC transition (see Table 1). This fact implies that equilibrium coexistence $\mathrm{M}+\mathrm{FCC}$ and $\mathrm{O}+\mathrm{FCC}$ lines cross at low-temperature and low-pressure (Figure 5b) and, according to Bakhuis Roozeboom, ${ }^{44}$ the $\mathrm{M}^{\mathrm{m}}$ phase behaves monotropically for 
the whole temperature and pressure space. Several examples of overall monotropy can be found in the literature. ${ }^{45-49}$

As far as the tetragonal lattice found by Hara et al. ${ }^{21}$ at $10 \mathrm{kbar}$ throughout indexing 3 Bragg peaks, the pattern of the orthorhombic phase (Figure 1b) clearly shows that those peaks match the most intense peaks of the $\mathrm{O}^{\mathrm{s}}$ phase.

Another irrefutable experimental proof of the stabilization effect of pressure is obtained by compression and decompression of the monoclinic metastable phase at temperatures lower than $200 \mathrm{~K}$ and heating up at normal pressure. Following this detour the temperature of the phase transition is found at $217 \mathrm{~K}$, which corresponds to the $\mathrm{O}^{\mathrm{s}}$ to OD FCC transition (instead of $203.6 \mathrm{~K}$ of the $\mathrm{M}^{\mathrm{m}}$ OD FCC transition temperature).

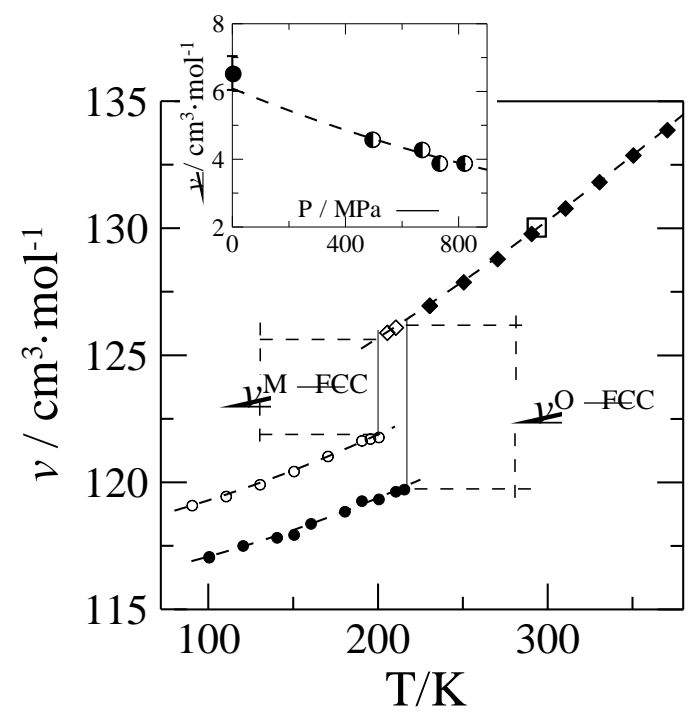

Figure 4. Molar volume for the orthorhombic stable $\mathrm{O}^{\mathrm{s}}$ (filled circles), monoclinic metastable $\mathrm{M}^{\mathrm{m}}$ (empty circles) and OD face-centered cubic phases as a function of temperature from X-ray measurements. Upper inset shows the volume variation as a function of pressure (half-filled circles) from ref. Hara et $\mathrm{al}^{22}$ and the volume change at normal pressure (filled circle) obtained in this work. Empty square represents the value for the OD FCC phase from ref. 27. 

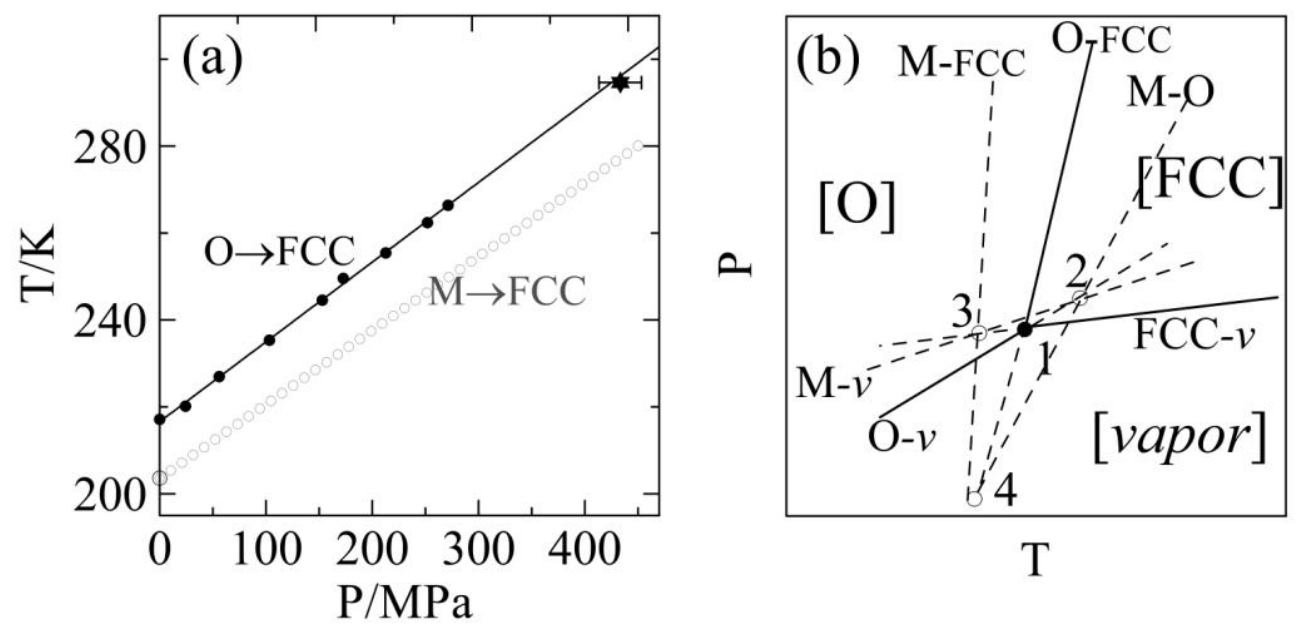

Figure 5. (a) Experimental Pressure-Temperature phase diagram for lowtemperature orthorhombic (filled circles) to FCC phase transition. Empty circle at normal pressure corresponds to the monoclinic $\mathrm{M}^{\mathrm{m}}$ to $\mathrm{FCC}$ phase transition (the equilibrium line is shown in grey). The start at high-pressure corresponds to the value read from the volume change as a function of pressure (figure 2 in ref. 22) for the decompression measurement. (b) Topological TemperaturePressure phase diagram with triple points $1(\mathrm{O}+\mathrm{FCC}+$ vapor $), 2(\mathrm{M}+\mathrm{O}+$ vapor $)$, $3(\mathrm{M}+\mathrm{FCC}+$ vapor $)$ and $4(\mathrm{M}+\mathrm{O}+\mathrm{FCC})$ according to Bakhuis Roozeboom. ${ }^{44}$

Table 3. Polynomial Equations $P=p_{\mathrm{o}}+p_{1} T+p_{2} T^{2}(T$ in $\mathrm{K}$ and $p$ in $\AA$ or in $\operatorname{deg}$ for $\beta$ parameter) to which the lattice parameters of the monolcinic $\left(\mathrm{M}^{\mathrm{m}}\right)$, orthorhombic $\left(\mathrm{O}^{\mathrm{s}}\right)$ and OD FCC phases were fitted as a function of temperature; $R$ is the Reliability Factor.

\begin{tabular}{ccccccc}
\hline Phase & $\begin{array}{c}\text { Temperature } \\
\text { Range }(\mathrm{K})\end{array}$ & Parameter & $p_{\mathrm{o}}$ & $p_{1} \cdot 10^{3}$ & $p_{2} \cdot 10^{5}$ & $\mathrm{R} \cdot 10^{8}$ \\
\hline $\mathrm{M}^{\mathrm{m}}$ & $90-205$ & $\mathrm{a} / \AA$ & $6.527(2)$ & $-0.04(3)$ & $0.20(1)$ & 4.5 \\
& & $\mathrm{~b} / \AA$ & $11.006(19)$ & $0.23(3)$ & $0.19(1)$ & 0.4 \\
& & $\mathrm{c} / \AA$ & $12.456(12)$ & $0.11(1)$ & $0.31(6)$ & 1.7 \\
& & $\beta /{ }^{\circ}$ & $118.73(8)$ & $-0.50(1)$ & $0.65(4)$ & 0.3 \\
$\mathrm{O}^{\mathrm{s}}$ & $90-215$ & $\mathrm{a} / \AA$ & $6.810(1)$ & $0.355(8)$ & - & 15 \\
& & $\mathrm{~b} / \AA$ & $10.690(23)$ & $0.30(3)$ & $0.17(9)$ & 5.6 \\
& & $\mathrm{c} / \AA$ & $10.537(10)$ & $0.23(1)$ & $0.16(4)$ & 1.3 \\
$\mathrm{FCC}$ & $205-400$ & $\mathrm{a} / \AA$ & $9.228(7)$ & $0.80(5)$ & $0.06(8)$ & 0.4 \\
\hline
\end{tabular}

From the lattice parameters as a function of temperature the intermolecular interactions can be enhanced throughout the isobaric thermal-expansion 
tensor. ${ }^{43,50,51}$ It is a symmetrical second-rank tensor, $d U_{i j}=\alpha_{i j} d T$, with non-zero eigenvalues on the diagonal. A small value of a tensor eigenvalue is commonly referred to as a "hard" direction, because it shows up small deformation $d U$ against temperature variation, $d T$, whereas a large value is referred to as "soft" direction because it indicates a large deformation. For a monoclinic lattice the tensor is completely defined by the principal coefficients, $\alpha_{1}, \alpha_{2}$, and $\alpha_{3}$, and an angle between the direction of one of the principal directions $\left(\alpha_{3}\right.$, in the present case) and the crystallographic axis $\boldsymbol{a}$, the $\alpha_{2}$ eigenvector being coincident with the 2-fold axis $\boldsymbol{b}$ of the crystal. For orthorhombic systems, eigenvectors are parallel to the mutually perpendicular crystal axes.

(a)

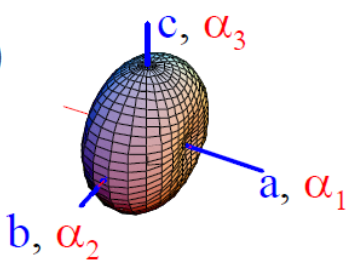

(b)

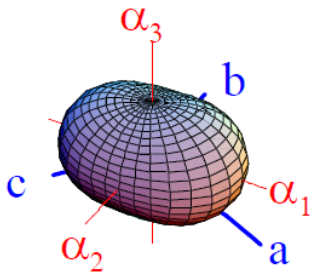

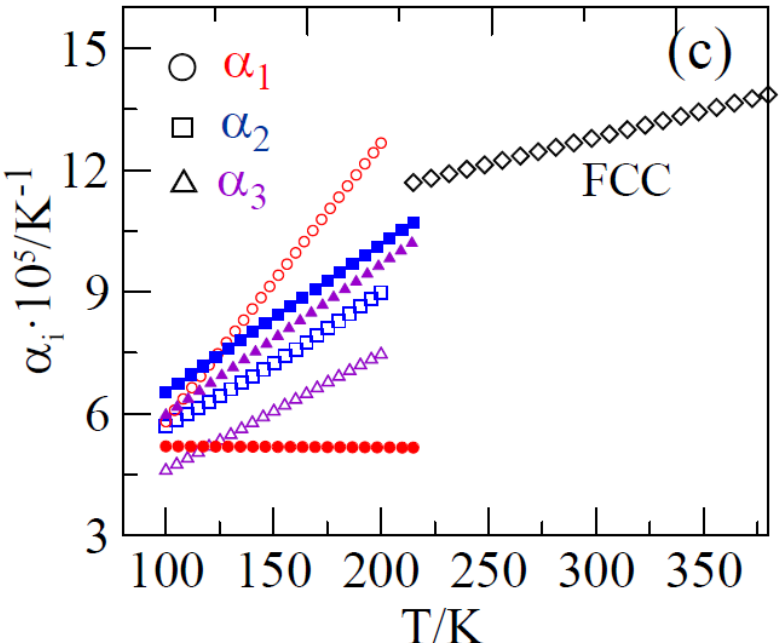

Figure 6. Figures (a) and (b) show the thermal-expansion tensors for orthorhombic and monoclinic phases, respectively, at $190 \mathrm{~K}$. (c) The eigenvalues $\alpha_{i}$ as a function of temperature for the orthorhombic (full symbols) and monoclinic (empty symbols) and the OD FCC (empty diamonds) phases.

Figure 6 shows the variation of the eigenvalues as a function of temperature for all the phases involved in 2O-A. The $\alpha_{1}$ direction in the $\mathrm{M}^{\mathrm{m}}$ phase, close to the [100] direction, is the soft direction, while the $\alpha_{3}$ direction is the hard direction. These eigenvectors $\alpha_{1}$ and $\alpha_{3}$ lie on the (0k0) monoclinic crystallographic plane (see Figure 7). From Figure 7a it can also see that the $\mathrm{O}$ atoms are related by a rotation of the molecule around a perpendicular axis to $\boldsymbol{a}$, being such an axis close to the $\alpha_{3}$ direction $\left(30.3^{\circ}\right)$, the hardest direction. 
Both monoclinic and orthorhombic structures can be described by stacking planes along the $c^{*}$ direction (see Figure 8) as it is evidenced from the $\mathrm{c}$ and $\operatorname{csin} \beta$ lattice values for the orthorhombic and monoclinic structures, respectively (Figure 3).

As for the orthorhombic structure, the $\mathrm{C}=\mathrm{O}$ bonds (the dipolar direction of the molecule) are sited in the (100) crystallographic plane and the smaller $\mathrm{O} \cdots \mathrm{H}$ intermolecular distances are $2.94 \AA$, larger than the van der Waals radii $(1.52 \AA$ and $1.20 \AA$ for $\mathrm{O}$ and $\mathrm{H}$, respectively), making the directions $\alpha_{2}$ and $\alpha_{3}$ softer. On the contrary, the hardest direction corresponds to [100] crystallographic direction $\left(\alpha_{1}\right)$ despite such a direction does not contain dipole-dipole interactions.

The equivalence of the occupancy factors for $\mathrm{O} 1$ and $\mathrm{O} 2$ atoms has a counterpart concerning the intermolecular interactions. Figure $7 \mathrm{~b}$ clearly shows that $\mathrm{C} \cdots \mathrm{O} 1(3.12 \AA)$ and $\mathrm{C} \cdots \mathrm{O} 2(3.26 \AA)$ form an square containing the $\boldsymbol{a}$ axis and making almost no difference between both distances, and thus interactions, as a consequence of the equal occupancy factor for both $\mathrm{O} 1$ and $\mathrm{O} 2$ atoms (0.25). Moreover, the distances $\mathrm{O} 1 \cdots \mathrm{O} 2$ within the described square are 2.58

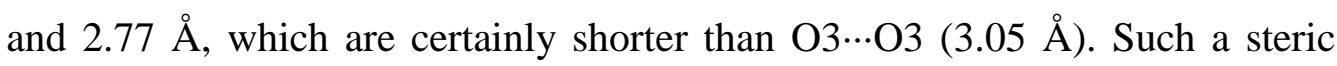
hindrance can give rise to the higher occupational factor for the $\mathrm{O} 3$ site when compared to $\mathrm{O} 1$ and $\mathrm{O} 2$ sites.

(a)

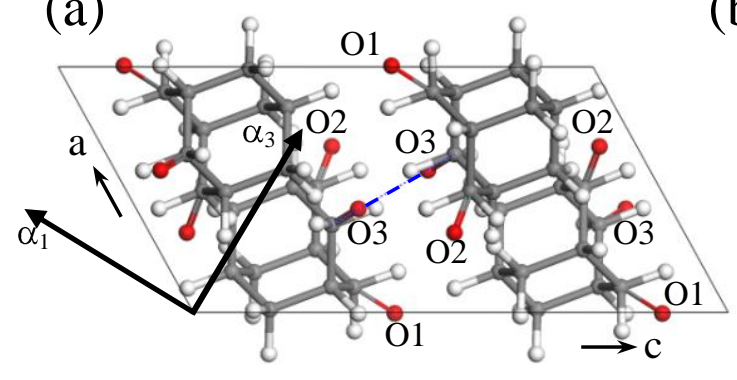

(b)

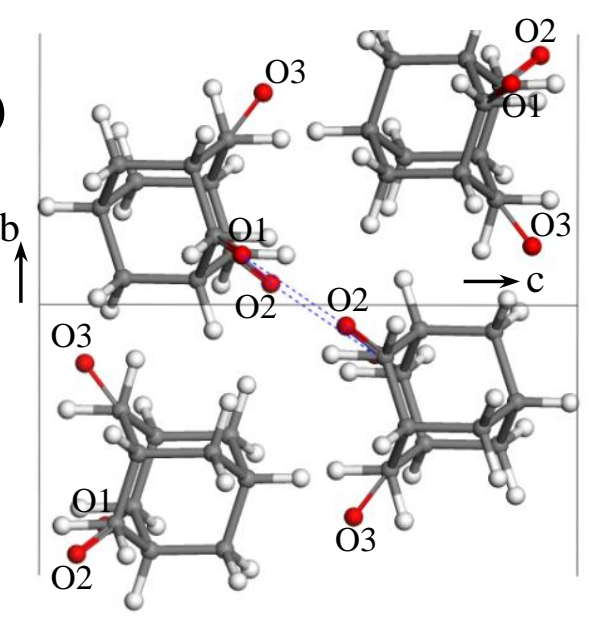


Figure 7. Projection of the monoclinic structure on the (0k0) crystallographic plane together with the eigenvectors $\alpha_{1}$ and $\alpha_{3}$ (a) and on the (0kl) plane (b). Dotted lines links the $\mathrm{O} 3 \cdots \mathrm{O} 3$ (a) and the $\mathrm{O} 1 \cdot . \mathrm{O} 1$ and $\mathrm{O} 2 \cdot . \mathrm{O} 2$ atoms (b).

As for the overall volume expansivity, $\alpha_{v}=\sum_{i=1}^{3} \alpha_{i}$ (not shown), the metastable monoclinic $\mathrm{M}^{\mathrm{m}}$ phase expands more than the stable orthorhombic $\mathrm{O}^{\mathrm{s}}$ stable phase $\left(27.8 \cdot 10^{-5} \mathrm{~K}^{-1}\right.$ and $24.3 \cdot 10^{-5} \mathrm{~K}^{-1}$ at $190 \mathrm{~K}$, respectively) as a consequence of the statistical disorder, a fact which is coherent with the highest packing (lower density) of the most stable phase (see Table 2).

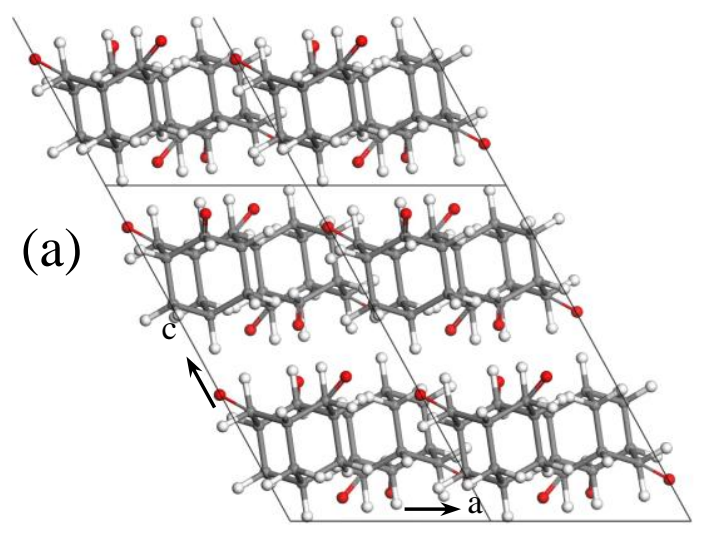

(b)

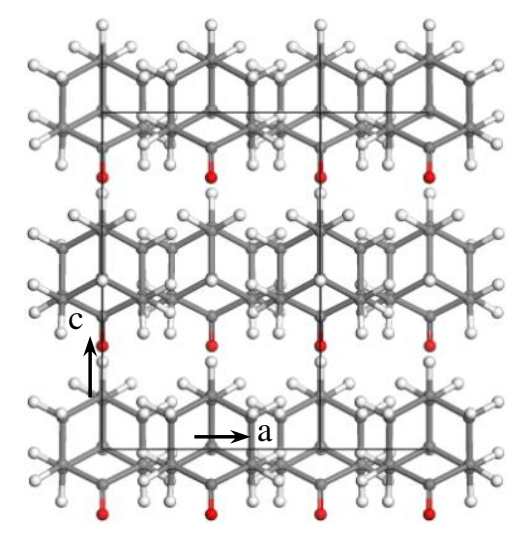

Figure 8. (0k0) crystallographic planes for the monoclinic (a) and orthorhombic (b) structures.

\section{Conclusions}

The intricate polymorphism of 2-adamantanone has been studied from $90 \mathrm{~K}$ to the liquid state as well as a function of pressure (until $300 \mathrm{MPa}$ ). The long time unknown phase relations and the low-temperature phases of 2-adamantanone have been determined. The ordered phase has been characterized as orthorhombic $\left(\mathrm{Cmc2}_{1}\right)$ with $\mathrm{Z}=4\left(\mathrm{Z}^{\prime}=0.5\right)$, whereas the metastable monoclinic 
phase $\left(P 2{ }_{1} / c\right)$ with $Z=4\left(Z^{\prime}=1\right)$ has been found to display a statistical intrinsic disorder concerning the site occupancy of the oxygen atom along three different sites (with fractional occupancies of 25\%, 25\% and 50\%). The stability of the orthorhombic phase in relation to the monoclinic phase has also been proved by means of the temperature-pressure phase diagram involving the orthorhombic and the orientationally disordered high-temperature cubic phase. The high-pressure behavior supports, in addition, that pressure easily stabilizes the orthorhombic phase. The volume change for the orthorhombic to OD cubic phase transition at normal pressure matches those obtained previously at highpressure and, together with the pressure behavior, enables to explain the tangled results of the literature. Through the analysis of the thermal-expansion tensor, the role played by the occupational oxygen disorder seems to explain the intermolecular interactions as well as the packing differences between both low-temperature crystalline phases.

\section{Acknowledgements}

This work was supported by the Spanish Ministry of Science and Innovation (Grant FIS2011- 24439) and the Catalan Government (Grant 2009SGR-1251).

\section{Supporting Information Available:}

Crystallographic information files (CIF) and fractional coordinates for monoclinic and orthorhombic phases of 2-adamantanone at $190 \mathrm{~K}$. This material is available free of charge via the Internet at http://pubs.acs.org.

\section{References}

1 McIntosh, G. C.; Yoon, M.; Berber, S.; Tománek, D. Phys. Rev. B 2004, 70, 045401 .

2 Wang, Y.Y.; Kioupakis, E.; Lu, X.H.; Wegner, D.; Yamachika, R.; Dahl, J. E.; Carlson, R. M. K.; Louie, S. G.; Crommie, M. F. Nature Mater. 2008, 7, 38.

3 Dahl, J. E.; S. G. Liu, S. G.; Carlson, R. M. K. Science 299, 96 (2003)

4 Yang, W. L.; Fabbri, J. D.; Willey, T. M.; Lee, J. R. I.; Dahl, J. E.; Carlson, R. M. K.; Schreiner, P. R.; Fokin, A. A.; Tkachenko, B. A.; Fokina, N. A.; 
Meevasana, W.; Mannella, N.; Tanaka, K.; Zhou, X. J.; van Buuren, T.;

Kelly, M. A.; Hussain, Z.; Melosh, N. A.; Shen, Z.-X. Science, 2007, 316, 1460 .

5 Du Q. -S.; Huang, R. -B. Current Protein and Peptide Science 2012, 13, 205.

6 Guo, W.; Galoppini, E.; Gilardi, R.; Rydja, G. I.; Chen, Y.H. Cryst. Growth \& Design 2001, 1, 231.

7 Vijayakumar, V.; Garg, A. B.; Godwal, B. K.; Sikka, S. K. Chem. Phys. Lett. 2000, 330, 275.

8 Arul Murugan, N.; Yashonath, S. J. Phys. Chem. B 2005, 109, 2014.

9 Pardo, L. C.; Tamarit, J. Ll.; Veglio, N.; Bermejo, F.J.; Cuello, G.J. Phys. Rev. B 2007, 76, 134203.

10 Timmermans, J. J. Phys. Chem. Solids 1961, 18, 1.

11 Salud, J.; López, D.O.; Barrio, M.; Tamarit, J. Ll.; Oonk, H.A.J.; Negrier, P.; Haget, Y. J. Solid State Chem. 1997, 133, 536.

12 Foulon, M.; Belgrand, T.; Gors, C.; More, M. Acta Cryst. B 1989, 45, 404.

13 Amoureux, J. P.; Bee, M.; Damien, D. C. Acta Cryst.B 1980, 36, 2633.

14 Cathiaux, D.; Sokolic, F.; Descamps, M.; Perera, A. Mol. Phys. 1999, 96, 1033.

15 Descamps, M. J. Phys. C-Solid St. Phys. 1982, 15, 7265.

16 Amoureux, J. P.; Bee, M. Acta Cryst.B 1980, 36, 2636

17 Affouard, F.; Willart, J. F.; Descamps, M. J. Non-Cryst. Solids, 2002, 307, 9.

18 Decressain, R.; Carpentier, L.; Cochin, E.; Descamps, M. J. Chem. Phys. 2005, 122, 034507.

19 Butler I. S.; Cole, H. B. R.; Gilson, D. F. R.; Harvey, P. D.; McFarlane, J.

D. J. Chem. Soc. Faraday Trans 2 1986, 82, 535.

20 Bazyleva A. B.; Blokhin, A. V.; Kabo, G. J.; Kabo, A. G.; Sevruk, V. M.

Thermochim. Acta 2006, 451, 65 .

21 Hara, K.; Osugi, J.; Taniguchi, Y.; Suzuki, K. High Temp-High Press 1980, $12,221$.

22 Hara, K.; Katou, Y.; Osugi, J. Bull. Chem. Jpn. 1981, 54, 687.

23 Harvey, P. D.; Butler, I. S.; Gilson, D. F. R.; Wong, P. T. T. J. Phys. Chem. 1986, $90,4546$. 
24 Romanini, M.; Negrier, P.; Tamarit, J. Ll.; Capaccioli, S.; Barrio, M.; Pardo, L. C.; Mondieig, D. Phys. Rev. B 2012, 85, 134201.

25 Bistricic, L.; Baranovic, G.; Mlinaric-Majerski, K. Spectrochimica Acta A 1998, 54, 1961.

26 Bistricic, L.; Pejov, L.; Baranovic, G. J. Molec. Struct. (Theochem) 2002, $594,79$.

27 Amoureux, J. P.; Bee, M. J. Phys. C: Solid St. Phys. 1980, 13, 3577.

28 Bee, M.; Amoureux, J. P. Mol. Phys. 1982, 47, 533.

29 Amoureux, J. P.; Castelain, M.; Bee, M.; Arnaud, B.; Shouteeten, M. L. J. Phys. C: Solid St. Phys. 1982, 15, 1319.

30 Amoureux, J. P.; Sahour, M.; Fernandez, C.; Bodart, P. Phys. Stat. Sol.(a) 1994, 143, 441.

31 Brand, R.; Lunkenheimer, P.; Loidl, A. J. Chem. Phys. 2002, 116, 10386.

32 Ito, T. Acta Cryst. B 1973, 29, 364.

33 Würflinger, A. Ber. Bunsen-Ges. Phys. Chem. 1975, 79, 1195.

34 Ballon, J.; Comparat, V.; Pouxe, J. Nucl. Instrum. Methods 1983, 217, 213.

35 Evain, M.; Deniard, P.; Jouanneaux, A.; Brec, R. J. Appl. Crystallogr. 1993, $26,563$.

36 Engel, G. E.; Wilke, S.; Konig, O.; Harris, K. D. M.; Leusen, F. J. J. J. Appl. Crystallogr. 1999, 32, 1169.

37 MS Modeling (Materials Studio), version 5.5: http://www.accelrys.com 38 Toraya, H.; Marumo, F. Mineral. J. 1981, 10, 211.

39 Rietveld, H. M. J. Appl. Crystallogr. 1969, 2, 65.

40 Levit, R.; Barrio, M.; Veglio, N.; Tamarit, J.Ll.; Negrier,P.; Pardo, L. C.;

Sanchez-Marcos, J.; Mondieig, D. J. Phys. Chem. B 2008,112, 13916.

41 Parat, B.; Pardo, L. C.; Barrio, M.; Tamarit, J.Ll.; Negrier,P.; Salud, J.;

López, D. O.; Mondieig, D. Chem. Mater. 2005, 17, 3359

42 Barrio, M.; Tamarit, J.Ll.; Negrier,P.; Pardo, L. C.; Veglio, N.; Mondieig,

D. New J. Chem. 2008, 32, 232.

43 Negrier, P.; Barrio, M.; Tamarit, J. Ll.; Veglio, N.; Mondieig, D. Cryst Growth Des. 2010, 10, 2793.

44 Salud, J.; Barrio, M.; Lopez, D. O; Alcobe, X.; Tamarit, J. Ll. J. Appl.

Cryst. 1998, 31, 748 . 
44 Bakhuis Roozeboom, H. W. Die heterogenen Gleichgewichte vom Standpunkte der Phasenlehre. Erstes Heft: Die Phasenlehre-Systeme aus einer Komponente. Braunschweig, Germany: Vieweg. 1901, pp. 183-189.

45 Perrin, M.-A.; Bauer, M.; Barrio, M.; Tamarit, J. Ll.; Céolin, R.; Rietveld, I. B. J. Pharm. Sci. 2013, 102, 2311.

46 Céolin, R.; Tamarit, J. Ll.; Barrio, M.; López, D. O.; Nicolaï, B.; Perrin, M.A.; Espeau, P.; Veglio, N. J. Pharm. Sci. 2008, 97, 3927.

47 Maruyama, M.; Kawabata, K.; Kuribayashi, N. J. Cryst. Growth 2000, 220, 161.

48 Tamarit, J. Ll.; Barrio, M.; Pardo, L. C.; Negrier, P.; Mondieig, D. J.Phys.: Condens. Matter, 2008, 20, 244110.

49 Pardo, L. C.; Barrio, M.; Tamarit, J. Ll.; López, D. O.; Salud, J.; Negrier, P.; Mondieig, D. Phys. Chem. Chem. Phys. 2001, 3, 2644.

50 Negrier, P.; Pardo, L. C.; Salud, J.; Tamarit, J. Ll.; Barrio, M.; Lopez, D. O.; Würflinger, A.; Mondieig, D. Chem. Mater. 2002, 14, 1921.

51 Weigel, D.; Beguemsi, T.; Garnier, P.; Berar, J. F. J. Solid State Chem. 1978, 23, 241. 


\section{For Table of Contents Use Only}

The stable and metastable lowtemperature phases of 2-adamantanone have been determined by X-ray powder diffraction as monoclinic $\left(P 2_{1} / c\right)$ and orthorhombic $\left(\mathrm{Cmc}_{1}\right)$, respectively. For the former, a statistical disorder concerning the site occupancy of the oxygen atom has been demonstrated.

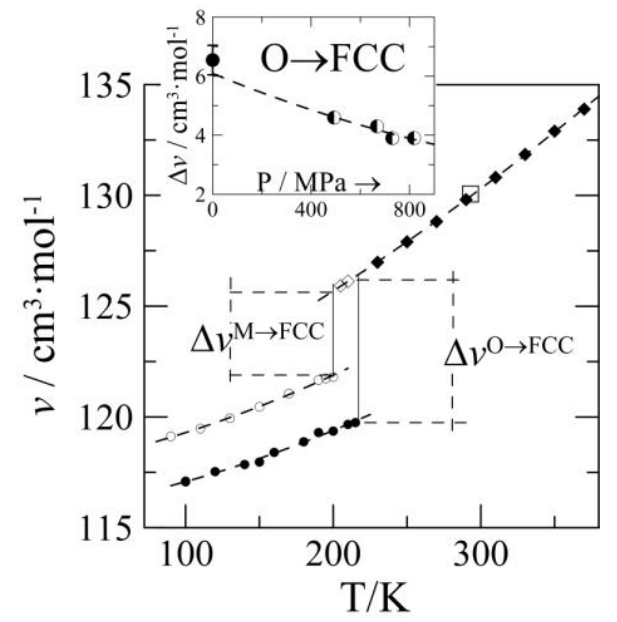

